\title{
The Changes of HIF-1 $\alpha$ and VEGF Expression After TACE in Patients With Hepatocellular Carcinoma
}

\author{
Kang Liu ${ }^{\mathrm{a}, \mathrm{b}}$, Xu-Li Min ${ }^{\mathrm{b}}$, Juan Peng ${ }^{\mathrm{b}}$, Ke Yang ${ }^{\mathrm{b}}$, Lin Yang ${ }^{\mathrm{b}}$,, Xiao-Ming Zhang
}

\begin{abstract}
As a common malignant tumor, hepatocellular carcinoma (HCC) has a high prevalence and is a serious threat to human health. The surgical resection rate of HCC is low, and the prognosis is poor. Although transarterial chemoembolization (TACE) is the main treatment for HCC patients who are not candidates for surgical resection, it is not considered a curative procedure. For HCC, poor TACE efficacy or TACE failure may be related to tumor angiogenesis of the residual disease. Among the many regulatory factors in tumor angiogenesis, hypoxia-inducible factor- $1 \alpha$ (HIF-1 $\alpha$ ) and vascular endothelial growth factor (VEGF) play vital roles in this process. In this paper, we conducted a review of the dynamic change and relevance of HIF- $1 \alpha$ and VEGF levels after TACE of HCC patients.
\end{abstract}

Keywords: Hepatocellular carcinoma; Transarterial chemoembolization; Vascular endothelial growth factor; Hypoxia-inducible factor- $1 \alpha$

\section{Introduction}

As a common malignant tumor, hepatocellular carcinoma (HCC) has a high prevalence and is a serious threat to human health [1]. Due to the hidden nature of onset of HCC, most patients are already at the advanced stage at the time of diagnosis and are not candidates for surgical resection, and thus the prognosis is poor [2-4]. During transarterial chemoembolization (TACE), chemotherapy drugs are perfused locally into the tumor; meanwhile, the blood supply to the tumor is blocked, leading to ischemia, hypoxia, and necrosis of tumor tissue [5].

Manuscript accepted for publication February 16, 2016

aDepartment of Pain Management, Xianyang Hospital, Yan'an University, Xianyang, Shanxi 712000, China

bepartment of Radiology, Affiliated Hospital of North Sichuan Medical College, Nanchong, Sichuan 637000, China

${ }^{\mathrm{c} C}$ Corresponding Author: Lin Yang, Department of Radiology, Affiliated Hospital of North Sichuan Medical College, Nanchong, Sichuan 637000, China. Email: linyangmd@163.com

doi: http://dx.doi.org/10.14740/jocmr2496w
Currently, the widely recognized Barcelona clinic liver cancer (BCLC) staging system recommends TACE as the standard of care for stage B HCC patients [6-8]. Studies have shown that TACE is effective for HCC and significantly improves the patient's survival [2, 5, 7, 9-12].

For HCC patients, poor TACE therapy or TACE failure may be related to tumor angiogenesis of the residual disease. Among the many regulators of tumor angiogenesis, hypoxiainducible factor- $1 \alpha$ (HIF-1 $\alpha)$ and vascular endothelial growth factor (VEGF) play vital roles in the regulation of tumor angiogenesis of the residual disease after TACE of HCC [13-17]. In this paper, we conducted a review of the dynamic change and relevance of HIF-1 $\alpha$ and VEGF levels after TACE of HCC patients.

\section{TACE in HCC}

A normal liver has a dual blood supply from the hepatic artery and portal vein; the portal vein provides $70-75 \%$ of the blood supply, and the hepatic artery provides $25-30 \%$ of the blood supply. In more malignant hepatic nodules, the blood supply originates less from the portal vein and more from the hepatic artery. HCC is mainly supplied by the hepatic artery. Moreover, advanced stages of HCC are correlated with a greater number of arteries in the HCC $[18,19]$. Computed tomography (CT) perfusion imaging has shown that HCC exhibits high arterial and low portal vein perfusions, which are valuable features in the diagnosis and differential diagnosis of $\operatorname{HCC}[20,21]$, as well as in the anatomical basis of TACE.

TACE involves both anti-cancer chemotherapy and embolization of tumor feeding arteries. Perfusion of anti-cancer chemotherapy drugs via feeding arteries increases the local drug concentration at the lesions and reduces the side effects of the drugs. Moreover, embolization of feeding arteries blocks the blood supply of the tumor, resulting in ischemia, hypoxia, and necrosis of the tumor tissue. Many factors affect the efficacy of TACE in the treatment of HCC, and tumor angiogenesis is an important factor. Kenji et al and our previous study have shown that TACE is effective for HCCs with a rich blood supply and is less effective for HCCs with a poor blood supply $[22,23]$; these tumors require a multi-disciplinary approach for effective treatment.

Effective monitoring of the treatment response of HCC 
patients to TACE affects the efficacy evaluation and development of the follow-up treatment regimen, including the time and frequency of repeat chemoembolization [24]. Previous World Health Organization (WHO) and response evaluation criteria in solid tumors (RECIST) criteria require measuring the change in tumor volume on imaging tests, which have significant shortcomings and drawbacks because in some HCC cases, the tumor volume may not change significantly, even though TACE or targeted therapy has been very effective (with no surviving tumor cells) [25]. In recent years, the evaluation of tumor viability has drawn more attention. The European Association for the Study of the Liver (EASL)-recommended modified RECIST (mRECIST) criteria have taken into account that treatment may cause tumor necrosis, and the posttreatment surviving tumors are defined as lesions with contrast uptake during the arterial phase [26].

\section{HCC and Tumor Angiogenesis}

The development, progression, and metastasis of solid tumors are closely related to angiogenesis (vessel-dependent). Studies have shown that the up-regulation of HIF-1 $\alpha$ expression is one of the predictive factors for a poor prognosis in many tumor patients [27-29]. For HCCs, nutrients are obtained from the host through tumor blood vessels, and cancer cells are transferred to the host through the tumor blood vessels so that cancer cells may grow in other sites or tissues of the body, ultimately leading to tumor metastasis [30]. As key inducing factors of tumor angiogenesis, HIF-l $\alpha$ and VEGF are involved in all stages of the process [30-33].

HIF-1 functions as a master regulator of oxygen homeostasis in most nucleated mammalian cells and is composed of the constitutively expressed HIF- $1 \beta$ subunit and the highly regulated HIF- $1 \alpha$ subunit. Subunit $\beta$ is constitutively expressed. Currently, it is believed that subunit $\alpha$, which exhibits sequence homology to subunit $\beta$, is the functional subunit that regulates the activation of HIF-1. The expression and transcriptional activity of the HIF-l $\alpha$ protein are subject to precise regulation of the intracellular oxygen level, which occurs on multiple levels, including mRNA expression, protein expression, nuclear localization, and transcriptional activation. Hypoxia stimulates HIF signaling pathways and, in particular, activates HIF-1 $\alpha$ [31], which plays a synergistic role in the expression of downstream genes (such as VEGF, p53, and erythropoietin (EPO)) and counteracts anti-proliferative and pro-apoptotic genes (such as NIX, BNIP3, and IGFBP3), thus significantly promoting tumor growth $[34,35]$.

Ferrara and Henzel [36] first isolated and purified VEGF from the supernatant of bovine pituitary follicular cell culture and named the protein. VEGF is a homodimer glycoprotein that consists of two single chains linked by disulfide bonds, and based on its structure, it is a member of the cystine knot growth factor superfamily. The genes that encode VEGF are located on the short arm of chromosome 6 . There are several VEGF splicing isoforms. Among these isoforms, VEGF121, VEGF165 and VEGF189 are the most prominent in human cells. VEGF is one of the most potent angiogenic growth factors. It is highly expressed in HCC patients, induces tumor an- giogenesis, and promotes tumor growth and metastasis. VEGF expression is stable and low in normal liver tissue [37, 38]. HIF- $1 \alpha$ binds to the promoter region of VEGF and induces transcription and expression of VEGF, resulting in neovascularization and an increased oxygen supply in the tumor tissue [39].

\section{Changes and Relevance of Serum HIF-1 $\alpha$ and VEGF Levels After TACE of HCC Patients}

TACE of HCC causes local hypoxia in the tumor, resulting in a series of adaptive changes in the transcription and expression of hypoxia response genes in tumor cells. Hypoxia response genes are mainly regulated by HIF- $1 \alpha$, which induces VEGF expression and promotes neovascularization [15, 4042]. Due to structural and functional defects, newly formed tumor blood vessels further aggravate hypoxia, and thereby form a vicious cycle leading to tumor recurrence and metastasis.

Studies have shown that dynamic changes in serum HIF$1 \alpha$ and VEGF levels occur after TACE of HCC patients [4146]. Jia et al [41] investigated the expression levels of serum HIF- $1 \alpha$ and VEGF pre- and post-TACE in patients with HCC, and correlations between prognosis factors and serum HIF- $1 \alpha$ as well as VEGF levels. Forty consecutive patients with HCC undergoing TACE were enrolled into the study. The study revealed that the expression levels of serum HIF- $1 \alpha$ and VEGF in $\mathrm{HCC}$ patients were significantly higher than those in control group. One day after TACE, both serum HIF- $1 \alpha$ and VEGF levels reached the peak values. One week post-TACE, expression levels of them were decreased, but still significantly higher than those before TACE. The levels of both HIF- $1 \alpha$ and VEGF in CR group 1 month post-TACE were significantly lower than those in PR + SD + PD group. Li et al [42] investigated the changes of VEGF level in the course of TACE in 45 HCC patients before, 1, 3, and 7 days after, and 1 month after TACE. The result showed that the VEGF levels increased significantly on the first day after TACE, and then decreased gradually on the third and seventh day post-TACE, but showing no statistical difference with pre-TACE VEGF levels. Ranieri et al [4751] showed similar results.

However, a few reports revealed that VEGF level increased more slowly after TACE administration [52, 53]. Suzuki et al [52] examined the level of VEGF, AST, ALT and LDH in sera of patients with HCC who underwent transcatheter arterial embolization (TAE) during the course of the treatment. Thirty-eight patients with HCC were studied. Peripheral blood samples were taken before and 1, 3 and 7 days after TAE. Although the level of AST, ALT and LDH reached the peak value within 1 day after TAE, VEGF level increased significantly 7 days later. Chao et al [53] investigated the serum IL-6 and VEGF level before and 1, 3, 5, 7, and 14 days after TACE in 41 patients with HCC. The result showed that the level of serum IL-6 increased rapidly and peaked on day 1 after TACE administration, whereas the level of VEGF increased more slowly and peaked on day 14 after TACE administration. 


\section{Changes and Relevance of HIF-1 $\alpha$ and VEGF Protein Expression in Tumor Tissues After TACE of HCC Patients}

Currently, there are a few reports of the changes in HIF-1 $\alpha$ and VEGF protein expression in tumor tissues after TACE of HCC patients. Xu et al [54] investigated the prognosis and expression of genes regulated by HIF-1 $\alpha$ in HCC patients who received preoperative TACE for the first time. The study revealed that HIF-1 $\alpha$ protein levels were significantly increased in TACE tissues. In addition, several other studies have reported that TACE stimulates tumor angiogenesis by up-regulating the expression of the VEGF protein [55-59]. Xiao et al [55] performed immunohistochemical staining of specimens from 79 HCC patients who underwent surgical resection after TACE and $57 \mathrm{HCC}$ patients who underwent surgical resection without TACE to detect the changes in VEGF protein expression. The results showed that the VEGF positive rate was significantly lower in patients treated with surgical resection alone than in patients who underwent TACE before surgical resection.

However, Farris et al [60] reported a different result. In the study, patients with HCCs receiving no locoregional therapy (LRT) (control) were compared with LRT treatment groups with conventional TACE (cTACE) or drug-eluting bead TACE (DEB TACE). Tumoral VEGF was significantly different between groups, with the control group having the highest degree of positivity. The study revealed that LRT leads to decreased tumoral VEGF.

In recent years, some researchers have conducted animal experiments to investigate the impact of TACE on HIF-1 $\alpha$ and VEGF protein expression. Virmani et al [61] tested the hypothesis that TAE induces expression of HIF-1 $\alpha$ within the same rabbit VX2 liver tumor. In their study, seven VX2 tumors were grown in the livers of five New Zealand white rabbits. Pre- and post-TAE tumor biopsy specimens along with post-TAE whole liver tumor sections were stained with an HIF-1 $\alpha$ antibody and analyzed to determine the percentage of HIF- $1 \alpha$ positive nuclei using a spectral unmixing system mounted on a high-powered microscope. The results indicated that TAE of liver tumors resulted in a statistically significant increase in the mean percentage of HIF- $1 \alpha$ expression. The study revealed that hypoxia caused by TAE of VX2 liver tumors activates HIF-1 $\alpha$, a transcription factor that regulates other pro-angiogenic factors. Zhou et al $[14,62,63]$ also reported similar results.

\section{Conclusion}

As potent factors of tumor angiogenesis, HIF-1 $\alpha$ and VEGF play important roles in the development, progression, and metastasis of $\mathrm{HCC}$ and are important for the efficacy evaluation of TACE of HCC patients and the development of individualized treatment regimens. The inclusion of monitoring of the changes in serum HIF- $1 \alpha$ and VEGF levels or HIF- $1 \alpha$ and VEGF protein expression in tumor tissues after TACE of HCC patients as part of the efficacy evaluation criteria has enhanced the evaluation of HCC treatment. In addition to these methods, in-depth studies that also adopt functional imaging techniques will help to improve the response evaluation criteria in solid tumors [64-70]. Furthermore, further researches are needed to investigate the dynamic changes in HIF-1 $\alpha$ expression after TACE of HCC patients and the roles of HIF- $1 \alpha$ in the mechanisms of recurrence and metastasis of HCC after TACE.

\section{Conflicts of Interest}

Authors or institutions have no conflicts of interest.

\section{Funding}

The study was supported by the Projects of Department of Science and Technology of Sichuan Province (2016JY0105).

\section{References}

1. Lau WY, Lai EC. Hepatocellular carcinoma: current management and recent advances. Hepatobiliary Pancreat Dis Int. 2008;7(3):237-257.

2. Llovet JM, Schwartz M, Mazzaferro V. Resection and liver transplantation for hepatocellular carcinoma. Semin Liver Dis. 2005;25(2):181-200.

3. Sant M, Allemani C, Santaquilani M, Knijn A, Marchesi F, Capocaccia R. EUROCARE-4. Survival of cancer patients diagnosed in 1995-1999. Results and commentary. Eur J Cancer. 2009;45(6):931-991.

4. Omyla-Staszewska J, Deptala A. Effective therapeutic management of hepatocellular carcinoma - on the basis of a clinical case. Contemp Oncol (Pozn). 2012;16(1):6063.

5. Wang YX, De Baere T, Idee JM, Ballet S. Transcatheter embolization therapy in liver cancer: an update of clinical evidences. Chin J Cancer Res. 2015;27(2):96-121.

6. EASL-EORTC clinical practice guidelines: management of hepatocellular carcinoma. J Hepatol. 2012;56(4):908943.

7. Bruix J, Sherman M. Management of hepatocellular carcinoma: an update. Hepatology. 2011;53(3):1020-1022.

8. Song do S, Nam SW, Bae SH, Kim JD, Jang JW, Song MJ, Lee SW, et al. Outcome of transarterial chemoembolization-based multi-modal treatment in patients with unresectable hepatocellular carcinoma. World J Gastroenterol. 2015;21(8):2395-2404.

9. Lewandowski RJ, Mulcahy MF, Kulik LM, Riaz A, Ryu RK, Baker TB, Ibrahim SM, et al. Chemoembolization for hepatocellular carcinoma: comprehensive imaging and survival analysis in a 172-patient cohort. Radiology. 2010;255(3):955-965.

10. Marelli L, Stigliano R, Triantos C, Senzolo M, Cholongitas E, Davies N, Tibballs J, et al. Transarterial therapy for hepatocellular carcinoma: which technique is more effective? A systematic review of cohort and randomized studies. Cardiovasc Intervent Radiol. 2007;30(1):6-25.

11. Lo CM, Ngan H, Tso WK, Liu CL, Lam CM, Poon RT, 
Fan ST, et al. Randomized controlled trial of transarterial lipiodol chemoembolization for unresectable hepatocellular carcinoma. Hepatology. 2002;35(5):1164-1171.

12. Rammohan A, Sathyanesan J, Ramaswami S, Lakshmanan A, Senthil-Kumar P, Srinivasan UP, Ramasamy R, et al. Embolization of liver tumors: Past, present and future. World J Radiol. 2012;4(9):405-412.

13. Liang B, Zheng CS, Feng GS, Wu HP, Wang Y, Zhao H, Qian J, et al. Correlation of hypoxia-inducible factor 1alpha with angiogenesis in liver tumors after transcatheter arterial embolization in an animal model. Cardiovasc Intervent Radiol. 2010;33(4):806-812.

14. Rhee TK, Young JY, Larson AC, Haines GK, 3rd, Sato KT, Salem R, Mulcahy MF, et al. Effect of transcatheter arterial embolization on levels of hypoxia-inducible factor-1alpha in rabbit VX2 liver tumors. J Vasc Interv Radiol. 2007;18(5):639-645.

15. Unruh A, Ressel A, Mohamed HG, Johnson RS, Nadrowitz R, Richter E, Katschinski DM, et al. The hypoxiainducible factor-1 alpha is a negative factor for tumor therapy. Oncogene. 2003;22(21):3213-3220.

16. Dames SA, Martinez-Yamout M, De Guzman RN, Dyson HJ, Wright PE. Structural basis for Hif-1 alpha /CBP recognition in the cellular hypoxic response. Proc Natl Acad Sci U S A. 2002;99(8):5271-5276.

17. Bausch D, Pausch T, Krauss T, Hopt UT, Fernandez-delCastillo C, Warshaw AL, Thayer SP, et al. Neutrophil granulocyte derived MMP-9 is a VEGF independent functional component of the angiogenic switch in pancreatic ductal adenocarcinoma. Angiogenesis. 2011;14(3):235243.

18. Yang ZF, Poon RT. Vascular changes in hepatocellular carcinoma. Anat Rec (Hoboken). 2008;291(6):721-734.

19. Kudo M, Tomita S, Kashida H, Mimura J, Okabe Y, Hirasa M, Ibuki Y, et al. [Tumor hemodynamics in hepatic nodules associated with liver cirrhosis: relationship between cancer progression and tumor hemodynamic change]. Nihon Shokakibyo Gakkai Zasshi. 1991;88(8):1554-1565.

20. Fischer MA, Kartalis N, Grigoriadis A, Loizou L, Stal P, Leidner B, Aspelin P, et al. Perfusion computed tomography for detection of hepatocellular carcinoma in patients with liver cirrhosis. Eur Radiol. 2015;25(11):3123-3132.

21. Ippolito D, Capraro C, Casiraghi A, Cestari C, Sironi S. Quantitative assessment of tumour associated neovascularisation in patients with liver cirrhosis and hepatocellular carcinoma: role of dynamic-CT perfusion imaging. Eur Radiol. 2012;22(4):803-811.

22. Kenji J, Hyodo I, Tanimizu M, Tanada M, Nishikawa Y, Hosokawa Y, Mandai K, et al. Total necrosis of hepatocellular carcinoma with a combination therapy of arterial infusion of chemotherapeutic lipiodol and transcatheter arterial embolization: report of 14 cases. Semin Oncol. 1997;24(2 Suppl 6):S6-71-S76-80.

23. Yang L, Zhang XM, Zhou XP, Tang W, Guan YS, Zhai $\mathrm{ZH}$, Dong GL. Correlation between tumor perfusion and lipiodol deposition in hepatocellular carcinoma after transarterial chemoembolization. J Vasc Interv Radiol. 2010;21(12):1841-1846.

24. Lim HK, Han JK. Hepatocellular carcinoma: evaluation of therapeutic response to interventional procedures. Abdom Imaging. 2002;27(2):168-179.

25. Therasse P, Arbuck SG, Eisenhauer EA, Wanders J, Kaplan RS, Rubinstein L, Verweij J, et al. New guidelines to evaluate the response to treatment in solid tumors. European Organization for Research and Treatment of Cancer, National Cancer Institute of the United States, National Cancer Institute of Canada. J Natl Cancer Inst. 2000;92(3):205-216.

26. Arora A, Kumar A. Treatment Response Evaluation and Follow-up in Hepatocellular Carcinoma. J Clin Exp Hepatol. 2014;4(Suppl 3):S126-129.

27. Du R, Lu KV, Petritsch C, Liu P, Ganss R, Passegue $\mathrm{E}$, Song $\mathrm{H}$, et al. HIFlalpha induces the recruitment of bone marrow-derived vascular modulatory cells to regulate tumor angiogenesis and invasion. Cancer Cell. 2008;13(3):206-220.

28. Isobe T, Aoyagi K, Koufuji K, Shirouzu K, Kawahara A, Taira T, Kage M. Clinicopathological significance of hypoxia-inducible factor-1 alpha (HIF-1alpha) expression in gastric cancer. Int J Clin Oncol. 2013;18(2):293-304.

29. Schwab LP, Peacock DL, Majumdar D, Ingels JF, Jensen LC, Smith KD, Cushing RC, et al. Hypoxia-inducible factor 1alpha promotes primary tumor growth and tumorinitiating cell activity in breast cancer. Breast Cancer Res. 2012;14(1):R6.

30. Mukozu T, Nagai H, Matsui D, Kanekawa T, Sumino Y. Serum VEGF as a tumor marker in patients with HCVrelated liver cirrhosis and hepatocellular carcinoma. Anticancer Res. 2013;33(3):1013-1021.

31. Li Z, Hu DY, Chu Q, Wu JH, Gao C, Zhang YQ, Huang YR. Cell apoptosis and regeneration of hepatocellular carcinoma after transarterial chemoembolization. World J Gastroenterol. 2004;10(13):1876-1880.

32. Chen Y, Zhang L, Pan Y, Ren X, Hao Q. Over-expression of semaphorin4D, hypoxia-inducible factor-1alpha and vascular endothelial growth factor is related to poor prognosis in ovarian epithelial cancer. Int J Mol Sci. 2012;13(10):13264-13274.

33. Finlay DK, Rosenzweig E, Sinclair LV, Feijoo-Carnero C, Hukelmann JL, Rolf J, Panteleyev AA, et al. PDK1 regulation of $\mathrm{mTOR}$ and hypoxia-inducible factor 1 integrate metabolism and migration of CD8 + T cells. J Exp Med. 2012;209(13):2441-2453.

34. Kim JW, Evans C, Weidemann A, Takeda N, Lee YS, Stockmann C, Branco-Price C, et al. Loss of fibroblast HIF-1alpha accelerates tumorigenesis. Cancer Res. 2012;72(13):3187-3195.

35. Xu LF, Ni JY, Sun HL, Chen YT, Wu YD. Effects of hypoxia-inducible factor-1alpha silencing on the proliferation of CBRH-7919 hepatoma cells. World J Gastroenterol. 2013;19(11):1749-1759.

36. Ferrara N, Henzel WJ. Pituitary follicular cells secrete a novel heparin-binding growth factor specific for vascular endothelial cells. Biochem Biophys Res Commun. 1989;161(2):851-858.

37. Huang GW, Yang LY, Lu WQ. Expression of hypoxia-inducible factor 1alpha and vascular endothelial growth factor in hepatocellular carcinoma: Impact on 
neovascularization and survival. World J Gastroenterol. 2005;11(11):1705-1708.

38. Wang D, Luo L, Chen W, Chen LZ, Zeng WT, Li W, Huang XH. Significance of the vascular endothelial growth factor and the macrophage migration inhibitory factor in the progression of hepatocellular carcinoma. Oncol Rep. 2014;31(3):1199-1204.

39. Freedman SJ, Sun ZY, Poy F, Kung AL, Livingston DM, Wagner G, Eck MJ. Structural basis for recruitment of $\mathrm{CBP} / \mathrm{p} 300$ by hypoxia-inducible factor-1 alpha. Proc Natl Acad Sci U S A. 2002;99(8):5367-5372.

40. Sergio A, Cristofori C, Cardin R, Pivetta G, Ragazzi R, Baldan A, Girardi L, et al. Transcatheter arterial chemoembolization (TACE) in hepatocellular carcinoma (HCC): the role of angiogenesis and invasiveness. Am J Gastroenterol. 2008;103(4):914-921.

41. Jia ZZ, Jiang GM, Feng YL. Serum HIF-1alpha and VEGF levels pre- and post-TACE in patients with primary liver cancer. Chin Med Sci J. 2011;26(3):158-162.

42. Li X, Feng GS, Zheng CS, Zhuo CK, Liu X. Expression of plasma vascular endothelial growth factor in patients with hepatocellular carcinoma and effect of transcatheter arterial chemoembolization therapy on plasma vascular endothelial growth factor level. World J Gastroenterol. 2004;10(19):2878-2882.

43. Leelawat K, Laisupasin P, Kiatdilokrut A, Pongtongpool T, Narong S, Samkhumphim N, Ket-Horm S. The effect of doxorubicin on the changes of serum vascular endothelial growth factor (VEGF) in patients with hepatocellular carcinoma after transcatheter arterial chemoembolization (TACE). J Med Assoc Thai. 2008;91(10):1539-1543.

44. Jia ZZ, Huang YQ, Feng YL, Jiang GM. [Correlations between serum hypoxia inducible factor-1alpha, vascular endothelial growth factor and computed tomography perfusion imaging at pre-and post-TACE in patients with primary hepatic carcinoma]. Zhonghua Yi Xue Za Zhi. 2013;93(19):1472-1475.

45. Shim JH, Park JW, Kim JH, An M, Kong SY, Nam BH, Choi JI, et al. Association between increment of serum VEGF level and prognosis after transcatheter arterial chemoembolization in hepatocellular carcinoma patients. Cancer Sci. 2008;99(10):2037-2044.

46. Xiong ZP, Yang SR, Liang ZY, Xiao EH, Yu XP, Zhou SK, Zhang ZS. Association between vascular endothelial growth factor and metastasis after transcatheter arterial chemoembolization in patients with hepatocellular carcinoma. Hepatobiliary Pancreat Dis Int. 2004;3(3):386-390.

47. Ranieri G, Ammendola M, Marech I, Laterza A, Abbate I, Oakley C, Vacca A, et al. Vascular endothelial growth factor and tryptase changes after chemoembolization in hepatocarcinoma patients. World J Gastroenterol. 2015;21(19):6018-6025.

48. Guo JH, Zhu X, Li XT, Yang RJ. Impact of serum vascular endothelial growth factor on prognosis in patients with unresectable hepatocellular carcinoma after transarterial chemoembolization. Chin J Cancer Res. 2012;24(1):3643.

49. Hsieh MY, Lin ZY, Chuang WL. Serial serum VEGF-A, angiopoietin-2, and endostatin measurements in cirrhotic patients with hepatocellular carcinoma treated by transcatheter arterial chemoembolization. Kaohsiung J Med Sci. 2011;27(8):314-322.

50. Liu J, Yi J. Relationship between the changes of VEGF level and dendritic cells in peripheral blood of patients with hepatocellular carcinoma after transcatheter arterial chemoembolization. J Huazhong Univ Sci Technolog Med Sci. 2007;27(1):58-60.

51. Xiong ZP, Yang SR, Xiao EH, Zhou SK, Zhang ZS, Liang ZY. [Relation between vascular endothelial growth factor and reoccurence-metastasis after transcatheter arterial chemoembolization in hepatocellar carcinoma]. Zhonghua Zhong Liu Za Zhi. 2003;25(6):562-565.

52. Suzuki H, Mori M, Kawaguchi C, Adachi M, Miura S, Ishii H. Serum vascular endothelial growth factor in the course of transcatheter arterial embolization of hepatocellular carcinoma. Int J Oncol. 1999;14(6):1087-1090.

53. Chao Y, Wu CY, Kuo CY, Wang JP, Luo JC, Kao CH, Lee $\mathrm{RC}$, et al. Cytokines are associated with postembolization fever and survival in hepatocellular carcinoma patients receiving transcatheter arterial chemoembolization. Hepatol Int. 2013;7(3):883-892.

54. Xu W, Kwon JH, Moon YH, Kim YB, Yu YS, Lee N, Choi KY, et al. Influence of preoperative transcatheter arterial chemoembolization on gene expression in the HIF-1alpha pathway in patients with hepatocellular carcinoma. J Cancer Res Clin Oncol. 2014;140(9):1507-1515.

55. Xiao EH, Guo D, Bian DJ. Effect of preoperative transcatheter arterial chemoembolization on angiogenesis of hepatocellular carcinoma cells. World J Gastroenterol. 2009;15(36):4582-4586.

56. Shao G, Wang J, Zhou K, Yan Z. [Intratumoral microvessel density and expression of vascular endothelial growth factor in hepatocellular carcinoma after chemoembolization]. Zhonghua Gan Zang Bing Za Zhi. 2002;10(3):170173.

57. Bao Y, Feng WM, Tang CW, Zheng YY, Gong HB, Hou EG. Endostatin inhibits angiogenesis in hepatocellular carcinoma after transarterial chemoembolization. Hepatogastroenterology. 2012;59(117):1566-1568.

58. Wang B, Xu H, Gao ZQ, Ning HF, Sun YQ, Cao GW. Increased expression of vascular endothelial growth factor in hepatocellular carcinoma after transcatheter arterial chemoembolization. Acta Radiol. 2008;49(5):523-529.

59. Liao X, Yi J, Li X, Yang Z, Deng W, Tian G. Expression of angiogenic factors in hepatocellular carcinoma after transcatheter arterial chemoembolization. J Huazhong Univ Sci Technolog Med Sci. 2003;23(3):280-282.

60. Farris AB, 3rd, Dursun N, Dhanasekaran R, Coban I, McIntosh EB, Adsay NV, Kim HS. Tumoral and angiogenesis factors in hepatocellular carcinoma after locoregional therapy. Pathol Res Pract. 2012;208(1):15-21.

61. Virmani S, Rhee TK, Ryu RK, Sato KT, Lewandowski RJ, Mulcahy MF, Kulik LM, et al. Comparison of hypoxia-inducible factor-1alpha expression before and after transcatheter arterial embolization in rabbit VX2 liver tumors. J Vasc Interv Radiol. 2008;19(10):1483-1489.

62. Zhou B, Wang J, Yan Z. Ginsenoside Rg3 attenuates hepatoma VEGF overexpression after hepatic artery em- 
bolization in an orthotopic transplantation hepatocellular carcinoma rat model. Onco Targets Ther. 2014;7:19451954.

63. Zhang L, Liu FY, Fu JX, Duan F, Fan QS, Wang MQ. Hepatic arterial administration of sorafenib and iodized oil effectively attenuates tumor growth and intrahepatic metastasis in rabbit VX2 hepatocellular carcinoma model. Int J Clin Exp Pathol. 2014;7(11):7775-7781.

64. Bozgeyik Z, Onur MR, Poyraz AK. The role of diffusion weighted magnetic resonance imaging in oncologic settings. Quant Imaging Med Surg. 2013;3(5):269-278.

65. Goshima S, Kanematsu M, Noda Y, Kondo H, Watanabe $\mathrm{H}$, Bae KT. Diffusion kurtosis imaging to assess response to treatment in hypervascular hepatocellular carcinoma. AJR Am J Roentgenol. 2015;204(5):W543-549.

66. Park YS, Lee CH, Kim JH, Kim IS, Kiefer B, Seo TS, Kim KA, et al. Using intravoxel incoherent motion (IVIM) MR imaging to predict lipiodol uptake in patients with hepatocellular carcinoma following transcatheter arterial chemoembolization: a preliminary result. Magn Reson Imaging. 2014;32(6):638-646.
67. Yang L, Zhang XM, Tan BX, Liu M, Dong GL, Zhai ZH. Computed tomographic perfusion imaging for the therapeutic response of chemoembolization for hepatocellular carcinoma. J Comput Assist Tomogr. 2012;36(2):226230 .

68. Kaufmann S, Schulze M, Spira D, Horger M. Comparison of volume perfusion computed tomography and contrastenhanced ultrasound for assessment of therapeutic effect of transarterial chemoembolization in patients with hepatocellular carcinoma: a preliminary report. Acta Radiol. 2016;57(1):8-12.

69. Ippolito D, Fior D, Bonaffini PA, Capraro C, Leni D, Corso R, Sironi S. Quantitative evaluation of CT-perfusion map as indicator of tumor response to transarterial chemoembolization and radiofrequency ablation in HCC patients. Eur J Radiol. 2014;83(9):1665-1671.

70. Ippolito D, Bonaffini PA, Ratti L, Antolini L, Corso R, Fazio F, Sironi S. Hepatocellular carcinoma treated with transarterial chemoembolization: dynamic perfusion-CT in the assessment of residual tumor. World J Gastroenterol. 2010;16(47):5993-6000. 